\title{
SUPPORTING THE DYNAMIC STRUCTURES OF CEP SERVICES
}

\author{
Dr.-Ing. Volker Stich \\ Research Institute for Operations Management - FIR, Aachen, GERMANY \\ st@fir.rwth-aachen.de \\ Dipl.-Wi.-Ing. Patrick Wader MBA \\ Research Institute for Operations Management - FIR, Aachen, GERMANY \\ wa@fir.rwth-aachen.de
}

This document presents the challenges the CEP market (Courier, Express and Parcel) currently faces. Market growth, customer expectations, organizational structures and technological advancement are explained as factors. Different states of dynamics regarding structures and decision making within this market are presented and explained. These states are static, semi-static and dynamic. $A$ research project with the goal of developing a supporting infrastructure to allow for a higher level of dynamics in the CEP sector is presented. Logistical, technological and ergonomical aspects are integrative view points of the project.

\section{INTRODUCTION}

The business structures of delivery services in the CEP business (Courier, Express and Parcel) move further towards becoming virtual organizations. Today, subcontracting and franchising are common structural set-ups of CEP companies. Through technological advancements virtual organizations of a higher degree could be reached in this sector.

An open infrastructure that would allow for a higher level of dynamics does not fully exist, thus hindering the creation of smaller and more flexible units. In this paper today's challenges in the CEP sector are analyzed and structured. Specifics of the research project "ParcelMan" are explained that addresses these challenges.

\section{TODAY'S CHALLENGES IN THE CEP SECTOR}

Different factors bring upon change in the CEP sector. In this section the most important challenges are identified and discussed. Market growth, customer expectations, organizational structures and technological advancements play a key role. 


\subsection{Market growth}

The CEP markets in most western economies face continuos growth. Looking at Germany for example shows that the number of shipments in the CEP market in the years from 1995 to 1999 rose from about 1.35 billion to about 1.66 billion, an increase of 23\%. Revenues increased even further from DM 14.6 billion to DM 19.4 billion in the same period which equals a total gain of approximately $33 \%$ for that period (Manner-Romberg, 2001a).

Sector forecasts, that have proven to be very accurate in the past, show, that revenues will continue to raise and that the trend of the past will continue on into the future (Cremer, 2001a). Revenues for the year 2005 are forecasted to be around DM 26.5 billion which would equal growth of about $36 \%$ compared to the year 2000 (Manner-Romberg, 2001b).

As for the CEP market in the European Union, which accumulates to roughly $26 \%$ of the world's CEP market, prognosis show similar directions (MannerRomberg et al., 2001). Most notable the number of shipments will, in the next five years, grow faster than revenues, indicating moderate prize reductions in the market (Cremer, 2001a).

Analyzing the express portions of international shipments also leads to interesting conclusions: It is striking to see that express is growing much faster in relationship to more traditional means of transportation such as freight and regular mail. Longterm forecasts indicate that this growth will mean an increase of the express portion of the market from $9 \%$ in 1999 to $31 \%$ in 2019. Thus, smaller and faster shipments are more and more dominant in the future transportation market (Boeing, 2001).

\subsection{Customer expectations}

Demand for CEP shipments is on the rise. However, parallel to this intensification market expectations raise as well. Gone are the times when fast and reliable shipments were the only demands customers had. They now look for a higher logistical performance with a low tolerance for extra cost (Haldi and Schmidt, 2001). Among those expectations are guaranteed delivery times, smaller delivery time slots and same-day deliveries within a few hours (Cremer, 2001b).

Aside from purely logistical demands customers increasingly show demands for value added services. CEP companies started to offer payment functions when delivering shipments and are now starting to take over other responsibilities. This includes identification of customers when delivering legal documents. Those trends are expected to intensive in the future (Cremer, 2001b).

eCommerce brought expectations and changes of its own. Even though the impact on the CEP market up to today has proven to be smaller than many studies until recently believed it would be, logistical demands from end-consumers brought new challenges. Few customer that bought items online were willing to trade in this new convenience by having to pick up shipments at distant post offices: Shipments often could not reach them at home during business hours. In turn, box systems and different forms of decentralized pick point systems emerged (Bruckner and Wader, 2001; Stich and Wader, 2001). 
CEP companies are now faced with these new systems that are designed to enable asynchronous delivery to home addresses or decentralized, easily accessible locations. CEP companies first have to decide, which of these new systems they accept as delivery addresses. Legal matters, among others, are not solved completely. Employees have to familiarize themselves with different key systems of both electronic and manual nature that can also have impact on IT systems of the delivering company. Most importantly, CEP companies have to make strategic decisions whether to partner with new systems or not, as these systems can grow to become a competition in their very own market.

\subsection{Organizational structures}

The organizational set-ups of CEP companies show structures of higher complexity. Courier and express companies in most cases offer brand name, marketing, main infrastructure and such, and leave the last miles of the delivery process to subcontractors or other third parties. Franchising and subcontracting is very common. Only parcel services, in most cases, have a higher percentage of their own fleet and of drivers that they directly employ.

The CEP sector is dynamic and highly adaptive which is reflected in the organizational set-ups. Franchisees do switch, subcontractors may alter decisions. The usage of proprietary software is one method to create switching cost (MannerRomberg et al., 2001). In parallel, high fluctuations can be observed on the employee side. CEP companies have a high employee turnover especially among delivery drivers. Part-time positions and relatively low wages as well as physical and mental stress call their prize. Thus, companies often have to deal with a high number of employees that are fairly new to the company and its processes. There is a big lack of training and a high need for programs that can provide it.

\subsection{Technological advancements}

Looking at technology factors various changes can be observed. Track and trace systems have been set up by most CEP companies. These systems allow customers to find out where shipments are located. Usually these services consist of information on certain points in the delivery stage that have been passed, such as "left the depot", "cleared through customs" etc. Real time information about locations of moving vehicles or planes that carry shipments up to today are rare.

New logistical software and platforms offer other function. Through stand alone software or internet sites customers can find out by entering specific shipment characteristics, which provider services their needs the best and at what prize. Some internet platforms intend to serve as clearinghouses for various CEP companies. Those platforms would include finding the most suitable provider, taking and transferring orders, creating the appropriate documents, offering track and trace functions etc. They intend to give an overview on all shipments customers currently carry out.

As for new technology CEP companies currently employ in the actual delivery process, the use of mobile devices of different types have to be mentioned. Much has been experimented with these systems. Many of those experiments led to investments with negative payoffs. However, mobile devices can assist delivery 
employees at various tasks. They help to identify correct shipments through build in scanners. They record delivery signatures of customers. They help to transfer data to depots through telematic systems. However, many additional services still did not become popular for various reasons. One important factor for these shortcomings can be found in the use of proprietary solutions that do not use open standards (Manner-Romberg et al., 2001).

Tomorrow's advancements will further increase the possibilities for a more sufficient technology usage. Interface and data transfer technology such as blue tooth is becoming available just now. Third generation telecommunication standards promise to serve as platforms for various tasks. In this field, a tremendous potential can be found for CEP companies and their delivery processes in particular. Today, almost every person owns and uses a mobile phone of GSM-standard. This is likely to change throughout the next years to mobile phones of UMTS-standard. Thus, customers and employees will have a new type of technology at hand without the necessity of big investments by CEP companies. These technological improvements build a foundation for enhanced services to customers and an enhanced service production of employees at the same time.

\section{DIFFERENT STATES OF DELIVERY SERVICES}

Different states of delivery services can be identified when analyzing the changes in the CEP markets. In order to analyze these states two vantage points are helpful: First, states will be discussed from the point of view of the delivery unit itself. Second, states are described from a customer's point of view.

\subsection{Delivery unit vantage point}

Looking at the structure of delivery services different states can be identified. This is first carried out from a delivery unit/ employee point of view:

\subsubsection{Static state}

In this first state, drivers are contract-bound and directly employed by the CEP company. Planing activities are carried out centrally or by regional planing offices in depots. Shipments are delivered through drop-lists, that the drivers have to fulfill. There are almost no decentralized planing activities. This is a common form of organizational set-up in the parcel business today.

\subsubsection{Semi-static state}

In this middle state, some decentralization has taken place. The delivery unit can be a subcontractor or a franchisee in a franchise organization. This is a very dominant organizational form in the courier and express business today. As there are more local responsibilities, local units will carry out planing activities as well. E.g. they will decide on the allocation of shipments to vehicles/ routes and the sequencing within routes themselves. 


\subsubsection{Dynamic state}

The delivery unit, only one person in the purest dynamic form, will run his/ her own business. On the one hand, this is the most decentralized state of all. However, this is also the most dynamic one. With the most responsibility given to small units, drivers can use all data available to make decisions: They can accept or deny new possible orders/ shipments. They can locally carry out the dynamic and adaptive route planning and scheduling that is necessary. They can work for just one or for different companies that provide the rest of the infrastructure etc.

\subsection{Customer vantage point}

A similar assessment can be carried out from a customer's point of view. Here, the degree of available information and possible decisions that are based upon them help to draw conclusions. From this perspective also, three different states are considered. These states show, for the extreme occurrences static and dynamic, a high level of similarity if compared to the states mentioned above. However, the change of perspective is useful in order to further describe differences among the three states.

\subsubsection{Static state}

In this state, customers can not ask for changes in the way shipments reach them. Once an order is placed, it has a specified delivery address and it will reach this location on a predefined route. Addresses and delivery times for example are defined when senders start shipping an item. The receiver plays a passive role and can not make decisions.

\subsubsection{Semi-static state}

In this state, information transparency is introduced through track and trace systems. This could also be called virtualization. Intended for the use of the sender, this information allows to follow a shipment on its path. E.g. the sender can check through the system, who signed as proof of delivery at the other end of the shipping process. However, if the tracking information is past on to the receiver early on in the shipping process, the receiver can use this information to incorporate it into his/ her planing activities.

Consider this example: A service worker is carrying out maintenance activities on machinery at a customer's site. He realizes that he runs short on a specific spare part, that was intended for the repair of a machine on one of the next service sites. He contacts his company to send replacement parts. If the company passes on important tracking information on when the shipment will arrive, the service worker can alter his schedule accordingly. However, he has no impact on when and where a shipment arrives once a shipping order has been placed.

\subsubsection{Dynamic state}

The most flexibility arises in a truly dynamic state. Here, senders and receivers have the opportunity to alter the delivery point and/ or time (within specified limits). They 
can make decisions on the delivery process itself. Going back to the above mentioned example, the service worker will pass on the information where he is currently located in order to have the shipment meet him at the next suitable interception point. He also knows, when approximately a delivery would be possible and can alter his scheduling of maintenance sites and/ or tasks accordingly. The big difference to the situation described above is this: Through the use of an information system he can alter the time and the place of receiving the shipment once new information becomes available.

Of course, there are limits to the degree of dynamics that can be offered in such a system. These limits are of structural, legal and economical nature. However, by designed an open and supporting infrastructure, much can be done to reach such a state. The limits need to be looked at in detail in order to derive specifications of what can be reached.

\section{SUPPORTING DYNAMIC STRUCTURES}

In an effort to address the challenges described above a research project has been set up. The main goals of the project called "ParcelMan" can be expressed as follows:

The project aims to establish a higher logistical delivery performance in the CEP sector. This will allow customers e.g. to agree upon a smaller delivery window and/ or to be able to alter delivery decisions while a delivery process is ongoing.

The logistical performance will be made possible through a more flexible and dynamic form of the delivery process. A pool of licensed drivers that can quickly decide to take up a certain delivery task or a set of tasks will be assisted through the usage of mobile devices and a planning and interface application that will run on these devices. Decisions that drivers will be able to make include, but are not limited to, whether to take up a certain task, how to align new tasks with existing tasks (sequencing and route) and, at a later stage in the project, pricing options. Thus, customers that demand a higher than standard delivery performance or alter delivery orders (e.g. regarding time and address) can be informed about restrictions, current availabilities, prices etc.

Decentralized structures are supported through the planning and interface application that will incorporate a set of market mechanisms. During the course of the project the application is prototypically designed together with the necessary infrastructure to assist individuals that act in these structures. The planning and interface application of course also offers the necessary gateways to planning applications at depots and other central points in the system.

The possibilities of today's and emerging technologies are combined with a strong focus on employees' needs. It is key that the logistical performance created through this approach will not only phrase an answer to higher customer expectations but will also systematically include the needs and necessities of the delivery personal. Through the design and implementation of a far reaching training program it will be guaranteed that employees involved in the delivery process can deliver this higher performance while at the same time being highly motivated, qualified and empowered.

The overall results of the project can be measured by evaluating stress of individuals acting in the system. The project aims to allow for a higher logistical 
performance while at the same time empowering employees and lowering stress in the system as a whole.

The project that started in October 2001 is made possible through research funds from the German Ministry of Education and Research $(\mathrm{BMB}+\mathrm{F})$. It has a duration of thirty months. In order to sufficiently cover the wide scope of the project, ten partners from different industry and research areas work together. The project is set up in six different sub-projects. Partners of the project can be assigned to three different areas. Figure 1 illustrates the interdisciplinary nature of the project.

First, the logistics/ organizational sector is present in the consortium through express companies and parcel services as well as logistical research partners. Second, the technology focus is covered through partners with the needed specific hardware and/ or software expertise as well as research capabilities. Third, there is a strong focus on employees working in delivery services/ ergonomics through various research and transfer partners.

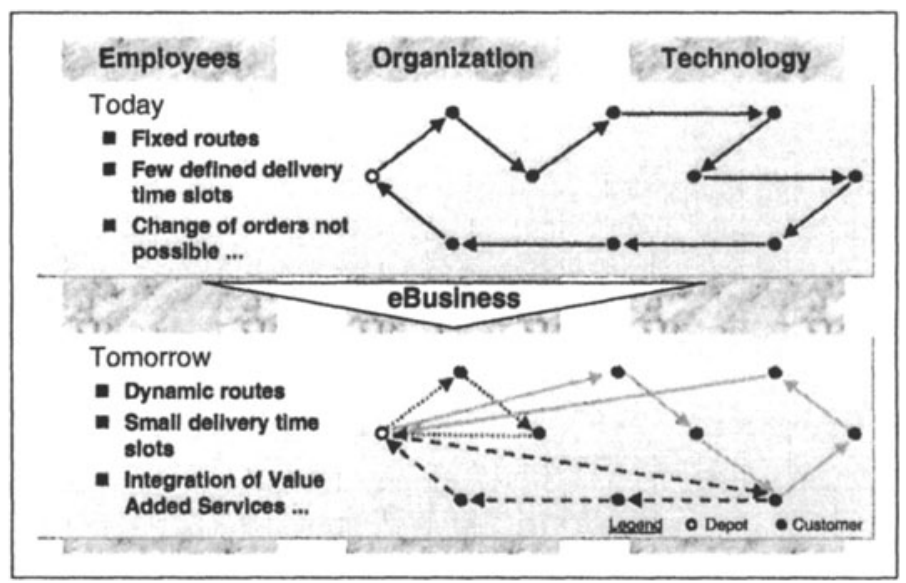

Figure 1 - Different components of the project

A multi-layer process model of the delivery itself and the accompanying planing and scheduling tasks is build as a baseline. On one layer the model describes detailed aspects of managing the distributed activities within the delivery network. Important differences of parcel and express companies are considered. Other projects address comparable modeling issues on a large scale (for example IMS projects Globeman or Prodnet). Some lessons learned are important to ParcelMan as well as there are similarities in nature, for example aspects regarding collaboration in after sales services (Hartel and Burger, 2001). However, ParcelMan addresses the rather small area of delivery services within the CEP industry. Adaptations of the model to other logistical activities are considered. However, a transfer to or from a manufacturing setting is not planned.

On the infrastructure side all necessary elements such as hardware requirements are specified. It is key to develop the infrastructure that supports distributed and decentralized work in a dynamic setup. Naturally, this also includes specifications for running the supporting mobile devices which are derived. Prototypical software 
applications to support work in the network and to provide service enhancing features are being developed. The infrastructure is based upon an open architecture.

All of these steps are accompanied by ergonomical studies. Process and job design, hardware and applications are geared towards the above mentioned goals. The build in training program for employees that work in delivery services of the CEP sector will enhance the chances of reaching them.

\section{CONCLUSIONS}

The CEP sector goes through a number of changes. Challenges currently faced are market growth, customer expectations, organizational structures and technological advancements.

Leaving the static state in order to reach a state of higher dynamics, it is necessary to build a supporting framework. The infrastructure described above will enable a higher logistical performance and will allow for dynamic decision making while at the same time support the people that carry out the delivery process. Thus, the formation of virtual organizations of a higher degree in this field is supported.

\section{Acknowledgments}

The project ParcelMan is made possible through research funds from the German Ministry of Education and Research $(\mathrm{BMB}+\mathrm{F})$ within the framework "Innovative job design - future of work". Project coaching is managed by a division of the German Aerospace Center (DLR-PT). Visit www.parcelman.de for details.

\section{REFERENCES}

1. Boeing. "World Air Cargo Forecast 2000/2001 - International Express". Seattle: Press Release of The Boeing Company, 2001.

2. Bruckner A, Wader P. "eLogistics - Alter Wein in neuen Schlauchen". In Proceedings of the 9th Unternehmerabend des FIR. Aachen, Germany. November 2001.

3. Cremer, Ludwig-Michael. "Neue Marktstudie beziffert das Wachstum der KEP-Branche in Deutschland bis 2005". Hamburg: Mitteilungen der MRU, 2001 (=2001a).

4. Cremer, Ludwig-Michael. "Das Zwei-Stunden-Zeitfenster bringt unser Geschäft nach vorn". In KEP Aktuell 2001; 4:6-11 ( $=2001 b)$.

5. Haldi J, Schmidt J. "Saturday delivery - Who provides it? Who needs it?". In Proceedings of the 9th Conference on Postal and Delivery Economics. Sorrento, Italy: June 2001.

6. Hartel I, Burger, G. "Virtual Service Enterprise - A model for virtual collaboration in after-sales service in the one-of-a-kind industry". In conference proceedings of the IMS project forum (IMS forum 2001), Ascona (CH), 8-10 October 2001.

7. Manner-Romberg H, Muller B, Weber P. "Demand for Communication - The increasing need for ways of efficient communication within the courier, express and postal markets". In Proceedings of the 9th Conference on Postal and Delivery Economics. Sorrento, Italy: June 2001.

8. Manner-Romberg, Horst. "Entwicklung des KEP-Marktes in Deutschland". Hamburg: Romberg Marktstudien, 2001 (=2001a).

9. Manner-Romberg, Horst. "Darstellung der Prognosen der Umsätze des deutschen KEP-Marktes bis 2005". Hamburg: Romberg Marktstudien, 2001 (=2001b).

10. Stich V, Wader P. "Herausforderung eLogistics". In Proceedings of the VDMA-Tagung Materialwirtschaft heute - Grundlage fur den Erfolg von morgen. Frankfurt, Germany: May 2001. 